\title{
EXCLUSÃO TERRITORIAL E VIOLÊNCIA
}

\author{
Raouel Rolnik \\ Arquiteta, Urbanista, Professora de Planejamento e Coordenadora do \\ curso de mestrado em urbanismo da PUC - Campinas
}

$\mathrm{S}$ e tivéssemos que apontar apenas um elemento - comum e o suficientemente forte - para definir cidades brasileiras histórica e regionalmente distintas, este seria sem dúvida a existência (e permanência no tempo) de contrastes profundos entre condições urbanas radicalmente distintas convivendo, muitas vezes conflitando, no interior da mesma cidade. Os morros e o asfalto na zona sul do Rio de Janeiro, o centro e as periferias da metrópole paulistana, o mangue e a orla na cidade à beira-mar são traduções territorialmente distintas da desigualdade de oportunidades urbanas que define nossas cidades.

Mais do que expressar diferenças econômicas e sociais, este contraste tem implicações profundas na forma e no funcionamento das cidades. $\mathrm{O}$ espraiamento em periferias precárias tem levado a uma necessidade absurda de viagens que atravessam a cidade, para conectar cotidianamente espaços de não-cidade às centralidades concentradoras de emprego, oportunidades econômicas, culturais, etc. Os efeitos urbanísticos decorrentes da persistência desta dinâmica são devastadores e ocorrem nos dois termos desta equação. Nas periferias (ou favelas, ocupações, invasões), o urbanismo é eternamente incompleto e, no mais das vezes, de risco.

Urbanismo de risco é aquele marcado pela inseguridade, quer do terreno, quer da construção, ou ainda da condição jurídica da posse daquele território. As terras onde se desenvolvem estes mercados de moradia para os pobres são, normalmente, justamente aquelas que, pelas características ambientais, são as mais frágeis, perigosas e difíceis de ocupar com urbanização: encostas íngremes, beiras de córregos, áreas alagadiças. As construções rara- mente são estáveis, e a posse quase nunca totalmente inscrita nos registros de imóveis e cadastros das prefeituras. O risco é, antes de mais nada, do morador: o barraco pode deslizar ou inundar com chuva, a drenagem e o esgoto podem se misturar nas baixadas - a saúde e a vida são assim ameaçadas. No cotidiano, são as horas perdidas no transporte, a incerteza quanto ao destino daquele lugar, o desconforto da casa e da rua.

Mas, neste caso, o urbanismo é de risco para a cidade inteira: por concentrar qualidades num espaço exíguo e impedir que elas sejam partilhadas por todos, os espaços mais bem equipados da cidade sentem-se constantemente ameaçados por cobiças imobiliárias, por congestionamentos, por assaltos.

Quando a erosão causada pelos desmatamentos e ocupações das encostas se acumula nas baixadas, rios e córregos, toda a cidade sofre com as enchentes. E quando o excesso de veículos e viagens provoca o colapso da circulação, é toda a cidade que pára.

Portanto, a exclusão territorial na cidade brasileira é mais do que a imagem da desigualdade, é a condenação de toda a cidade a um urbanismo de risco.

O objetivo deste texto é explorar o nexo entre urbanização de risco e violência urbana, que aparenta ser a face mais visível e recente desse modelo, utilizando a experiência concreta de diferentes cidades no Estado de São Paulo. Para construir tais relações, é importante entendermos a forma como diferentes padrões de desenvolvimento econômico e tendências demográficas contribuem para a geração de uma urbanização de risco, e como as políticas de planejamento e gestão urbana interagem com esta. 
A base empírica deste estudo é uma pesquisa estruturada para avaliar o impacto de regulação urbanística no funcionamento de mercados residenciais nas cidades do Estado de São Paulo com mais de 20 mil habitantes, conduzida em 1997-98 e financiada pela Fundação de Amparo à Pesquisa do Estado de São Paulo e o Lincoln Institute of Land Policy. ${ }^{1} \mathrm{~A}$ base da pesquisa foi um questionário enviado a 220 municípios, ${ }^{2}$ que foi respondido por 118 deles. Utilizando os dados desse questionário, combinados com uma tabulação especial do Censo de 1991, pudemos avaliar até que ponto instrumentos de planejamento e controle do uso do solo - que em princípio são desenhados para proporcionar cidades ambiental e socialmente equilibradas - atingem seus objetivos em municípios do Estado de São Paulo. O questionário explora os processos de planejamento e regulação urbana existentes nas cidades e as condições sob as quais eles foram produzidos e implementados. De posse dessa informação, organizamos um ranking de cidades, de acordo com a existência de diferentes legislações de controle de uso do solo, de forma que as cidades foram arroladas desde a "mais regulada" até a "menos regulada". ${ }^{3}$

As informações do Censo de 1991 foram utilizadas para construir um indicador "exclusão territorial" cruzando informações sobre condições na habitação. Com essa proposta, construiu-se uma matriz de quatro tipos de informação (referentes a condições de habitabilidade das casas, localização, infra-estrutura disponível e número de cômodos) transformadas em variáveis dicotômicas (adequada ou inadequada). ${ }^{4} \mathrm{O}$ indicador mede a porcentagem de domicílios em determinado município excluídos de condições urbanas mínimas.

O conceito de "exclusão territorial" foi construído procurando superar as dificuldades de leitura dos índices tradicionais de porcentagem de cobertura de infra-estrutura e indicadores gerais de condições de domicílios que, não territorializados, deixam de revelar uma imagem fiel das diferenças de condições urbanas no interior de um município. Cruzando os indicadores, poderemos esboçar mais claramente um quadro de onde a urbanização é "completa", e onde ela é precária ou incompleta por qualquer razão. Este indicador pode também contribuir para medirmos a segregação urbana, cruzando-o com dados de renda familiar, renda de chefes de família, cor e outras variáveis econômicas e sociais.

Escolhemos o termo "exclusão territorial" com a proposta óbvia de relacioná-lo com o conceito de exclusão social, muito mais do que com pobreza ou disparidades sociais.
Este conceito - que relaciona a acumulação de deficiências de várias ordens à vulnerabilidade - tem sido progressivamente utilizado em políticas públicas e pode ser entendido como a negação (ou o desrespeito) dos direitos que garantem ao cidadão um padrão mínimo de vida, assim como a participação em redes de instituições sociais e profissionais (Castel, 1995; Paugam, 1996). A exclusão social é vista como uma forma de analisar como e por que indivíduos e grupos não conseguem ter acesso ou beneficiar-se das possibilidades oferecidas pelas sociedades e economias. A noção de exclusão considera tanto os direitos sociais quanto aspectos materiais, abrangendo, portanto, não só a falta de acesso a bens e serviços - que significam a satisfação de necessidades básicas -, mas também a ausência de acesso a segurança, justiça, cidadania e representação política (Rodgers, 1995).

Para analisarmos melhor os resultados da pesquisa, cruzamos também os números obtidos com dados adicionais sobre as cidades: taxas de crescimento da população, valor adicionado per capita, receita municipal per capita e porcentagem de chefes de famílias ganhando menos de dois salários mínimos. Toda a informação foi processada em uma base de dados GIS para criarmos um mapa da exclusão territorial no Estado de São Paulo.

Em uma segunda fase da mesma pesquisa, foram feitos estudos de caso tendo como objeto de estudo três municípios escolhidos dentre os 118 - considerados representativos dos diferentes padrões de exclusão territorial encontrados na primeira etapa - para aprofundarmos a análise. Posteriormente, cruzamos os dados com indicadores de violência urbana, ${ }^{5}$ no âmbito de um grupo de trabalho organizado pelo Woodrow Wilson Center for International Scholars. ${ }^{6}$

\section{MAPEANDO A EXCLUSÃO TERRITORIAL NO ESTADO DE SÃO PAULO}

O Mapa 1 e a Tabela 1 dão uma idéia clara da regionalização da urbanização precária: as situações mais agudas de exclusão territorial encontram-se na fronteira da periferia da Região Metropolitana de São Paulo (EmbuGuaçu, 1,35\%; Arujá, 6,26\%; Francisco Morato, 7,46\%; e também Rio Grande da Serra, Cotia, Embu, Cajamar, entre outros), mas o fenômeno se repete nas cidades periféricas da Baixada Santista, Litoral Norte, Campinas, Vale do Paraíba e Sorocaba. A precariedade urbanística situase exatamente na periferia dos pólos mais dinâmicos e ricos de São Paulo, para onde se desconcentrou a grande 


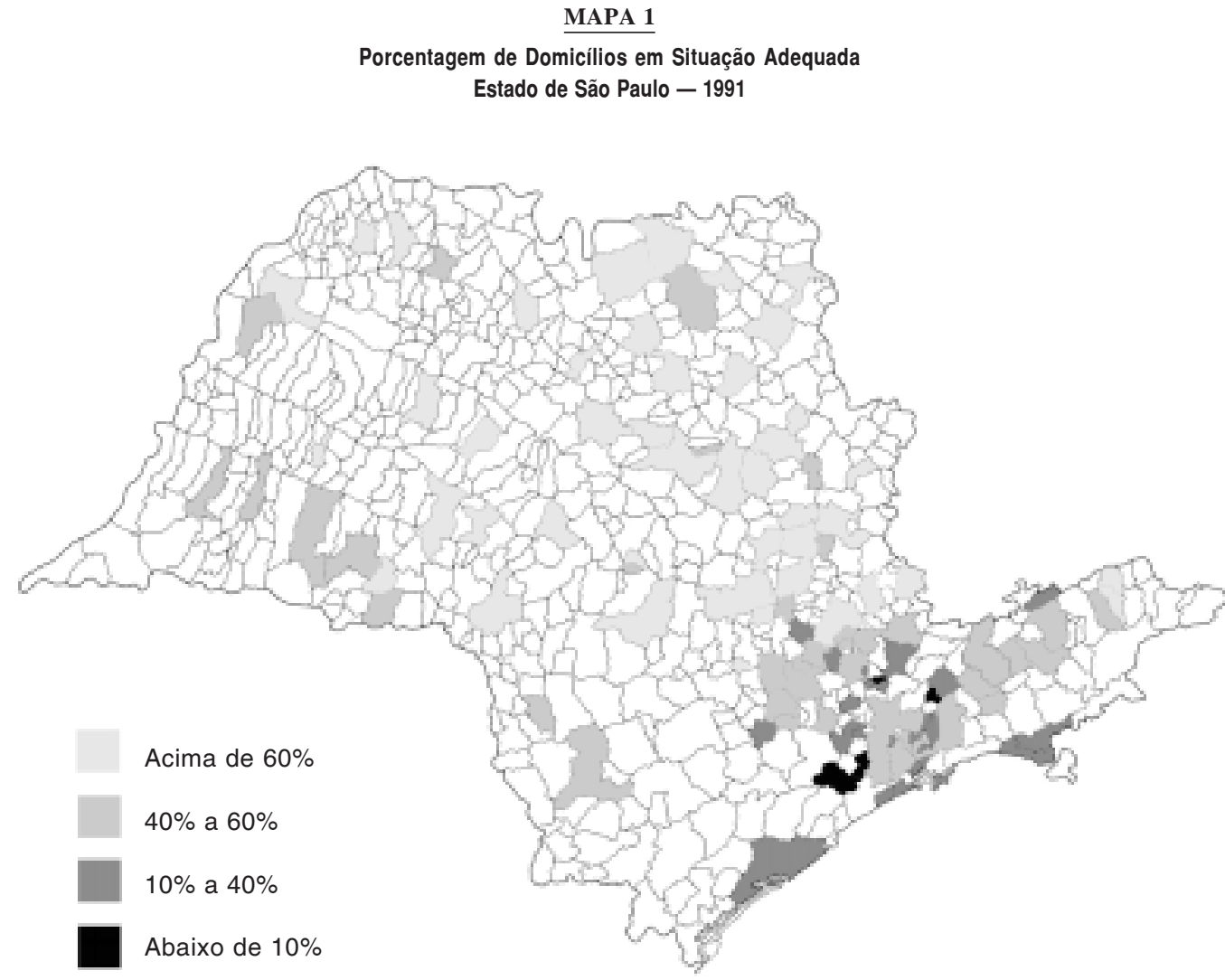

Fonte: Fundação IBGE. Tabulações Especiais do Censo de 1991.

indústria a partir dos anos 70. A região delimita, do ponto de vista urbanístico, o raio de um padrão de desenvolvimento urbano baseado em grandes zonas industriais, em sistemas de transporte sobre pneus e na expansão de assentamentos populares precários, espraiando exclusão territorial em suas fronteiras.

O cruzamento entre o valor adicionado per capita e a variável anterior reforça o argumento; entre as dez cidades com o maior valor adicionado per capita no Estado de São Paulo, seis pertencem ao grupo de cidades com o mais baixo percentual de domicílios em situação adequada. Nesses casos, as indústrias localizam-se em um município situado na periferia de um grande centro urbano e são conectadas a este por sistemas de estradas de rodagem (Monte Mor na periferia de Campinas; Mauá, na periferia do ABC; ou Cubatão, entre São Paulo e Santos). As indústrias atraem trabalhadores, mas, diante da mais absoluta ausência de controles de impacto ambiental, investimentos em expansão de infra-estrutura urbana ou provisão residencial contribuem para a degradação ambiental e a criação de mercados residenciais ilegais de baixa renda. Essas cidades economicamente vibrantes são então, cada vez mais, habitadas exclusivamente por uma população de baixa renda (já que executivos e gerentes vivem em centros próximos ou em São Paulo). Trata-se de um padrão de desenvolvimento econômico com altos níveis de concentração de renda e fortes desigualdades regionais, produzindo uma máquina voraz de exclusão territorial.

Outro padrão, também fortemente ligado à presença de riquezas, emerge nos locais turísticos localizados no interior da mesma mancha macrometropolitana. Cidades costeiras (como Guarujá e Caraguatatuba) ou estâncias de montanha (como Campos do Jordão) apresentam este padrão. Tais regiões foram urbanizadas por investidores imobiliários, oferecendo segundas residências para diferentes segmentos de mercado (de apartamentos de classe média a condomínios luxuosos e marinas), atraindo trabalhadores da construção civil e empregados domésticos - funcionando também como cidades-dormitório de centros industriais vizinhos (como Guarujá em relação ao Porto de Santos ou Caraguatatuba em relação ao Porto de São Sebastião). Nesses casos, situam-se municipalidades 
TABELA 1

Agrupamento dos Municípios, por Percentual de Adequações

Estado de São Paulo - 1991

\begin{tabular}{|c|c|c|c|}
\hline Municípios & Percentual de Adequações & Municípios & Percentual de Adequações \\
\hline Grupo 1 & & Morro Agudo & 55,99 \\
\hline Batatais & 74,00 & Itu & 55,88 \\
\hline Barra Bonita & 73,39 & São José dos Campos & 55,87 \\
\hline Cerquilho & 71,61 & Sorocaba & 55,76 \\
\hline Descalvado & 71,58 & Taubaté & 55,60 \\
\hline São José do Rio Preto & 70,72 & Lorena & 55,52 \\
\hline Lins & 70,13 & Indaiatuba & 55,31 \\
\hline Itápolis & 69,87 & Santa Bárbarad $\square$ Oeste & 55,14 \\
\hline Penápolis & 69,50 & Santo André & 54,88 \\
\hline Araras & 68,84 & Caçapava & 54,11 \\
\hline Santa Rita do Passa Quatro & 68,14 & Votuporanga & 54,11 \\
\hline Vargem Grande do Sul & 67,70 & São Paulo & 53,75 \\
\hline Socorro & 67,62 & São Bernardo do Campo & 53,51 \\
\hline Ribeirão Preto & 67,61 & Bragança Paulista & 53,40 \\
\hline Jaboticabal & 67,51 & Conchal & 52,57 \\
\hline Rio Claro & 67,50 & Taquarituba & 52,22 \\
\hline São Carlos & 67,14 & Pindamonhangaba & 52,06 \\
\hline Amparo & 66,51 & Salto & 50,18 \\
\hline Catanduva & 66,46 & Andradina & 49,90 \\
\hline Araraquara & 65,71 & Santa Branca & 48,46 \\
\hline Bebedouro & 65,58 & Jacareí & 47,41 \\
\hline Mogi-Guaçu & 65,43 & Votorantim & 47,11 \\
\hline Bauru & 65,22 & Mogi das Cruzes & 46,56 \\
\hline Santos & 65,12 & São Roque & 45,90 \\
\hline Santa Rosa do Viterbo & 64,61 & Itapeva & 45,38 \\
\hline Assis & 64,42 & Ribeirão Pires & 43,57 \\
\hline Pereira Barreto & 64,32 & Cândido Mota & 42,96 \\
\hline Marília & 64,28 & & \\
\hline Botucatu & 64,08 & Grupo 3 & \\
\hline Barretos & 63,96 & Salto de Pirapora & 39,46 \\
\hline Osvaldo Cruz & 63,87 & Itupeva & 38,39 \\
\hline São Joaquim da Barra & 63,64 & Poá & 37,34 \\
\hline Limeira & 63,12 & Santa Isabel & 37,17 \\
\hline Campinas & 62,67 & Mauá & 37,03 \\
\hline Fernandópolis & 62,07 & Campos do Jordão & 36,65 \\
\hline Garça & 62,06 & Atibaia & 36,38 \\
\hline Americana & 62,02 & Guarulhos & 34,46 \\
\hline Rio das Pedras & 61,60 & Iguape & 34,34 \\
\hline Guaíra & 61,56 & Guarujá & 34,11 \\
\hline Franca & 61,40 & Várzea Paulista & 33,38 \\
\hline Jales & 61,30 & Diadema & 31,80 \\
\hline Piracicaba & 61,30 & Suzano & 31,44 \\
\hline Santa Cruz do Rio Pardo & 61,08 & Monte Mor & 31,14 \\
\hline Cruzeiro & 61,03 & Mongaguá & 30,17 \\
\hline Cachoeira Paulista & 60,95 & Cajamar & 30,12 \\
\hline Matão & 60,80 & & \\
\hline Leme & 60,34 & Grupo 4 & \\
\hline Paraguaçu Paulista & 59,93 & Franco da Rocha & 28,89 \\
\hline Itatiba & 59,50 & São Sebastião & 28,36 \\
\hline Santa Cruz da Palmeiras & 58,95 & Caraguatatuba & 26,88 \\
\hline Américo Brasiliense & 58,88 & São Vicente & 26,00 \\
\hline \multirow[t]{2}{*}{ Presidente Prudente } & 58,62 & Santana de Parnaíba & 25,92 \\
\hline & & Embu & 23,06 \\
\hline Grupo 2 & & Cotia & 20,64 \\
\hline Igaraçu do Tietê & 57,93 & Praia Grande & 18,14 \\
\hline Rancharia & 57,41 & Rio Grande da Serra & 16,94 \\
\hline Valinhos & 57,11 & Cubatão & 10,07 \\
\hline Santo Anastácio & 56,83 & Francisco Morato & 7,46 \\
\hline Jundiaí & 56,66 & Juquitiba & 6,45 \\
\hline Porto Feliz & 56,42 & Arujá & 6,26 \\
\hline Vinhedo & 56,19 & Embu-Guaçu & 1,30 \\
\hline
\end{tabular}

Fonte: Fundação IBGE. Censo Demográfico 1991/Tabulação Especial Aurílio Caiado. 
com os mais baixos valores adicionados per capita, vizinhas de municipalidades com os mais altos (Mapa 2).

O padrão de exclusão territorial tem evidentemente a ver com a concentração de renda, pois, como vimos, as piores condições do Estado ocorrem nas áreas mais desenvolvidas e ricas.

Porém, a distribuição de renda não explica tudo, pois outras regiões do Estado de São Paulo com um nível mais baixo de exclusão territorial possuem mais ou menos a mesma estrutura de renda, ou, em algumas elas, os salários dos mais pobres são ainda mais baixos. ${ }^{7}$ Para compreendermos um modelo de desenvolvimento urbano que reproduz continuamente novas fronteiras de precariedade, é importante considerar como funcionam os mercados de terras, assim como o impacto do planejamento e regulação do uso do solo na configuração desses mercados.

\section{LEGISLAÇÃO URBANÍSTICA E MERCADOS INFORMAIS DE TERRAS EM CIDADES INDUSTRIAIS: AS RELAÇÕES PERVERSAS}

O caso de Diadema tipifica o processo da grande expansão industrial na Região Metropolitana de São Paulo. Quando a indústria chega a Diadema (nos anos 60 e 70), acelera-se o crescimento demográfico, gerando uma expansão horizontal de grandes proporções, que não cria exatamente um espaço urbano.

Diadema era uma cidade de 12.000 habitantes em 1960. Em 1971, uma nova estrada ligando São Paulo ao Porto de Santos foi construída, cruzando o território da cidade e atraindo pequenas e médias plantas industriais, satélites das grandes fábricas de São Bernardo. Por sua localização na periferia sudeste da metrópole, Diadema recebeu apenas migrantes de baixa renda. Na ausência de um grupo significativo de alta ou mesmo média renda, configuraram-se apenas dois segmentos no mercado de terras: um para usos industriais e outro para loteamentos residenciais de baixa renda.

Em 1973, um Plano Diretor para a cidade foi aprovado, definindo uma regulação do uso do solo, na qual mais de dois terços das terras do município - as áreas mais bem urbanizadas - foram destinadas para usos industriais. Além da regulação municipal, em 1976, uma lei estadual de preservação ambiental para a proteção das áreas de mananciais da urbanização excluiu 724 hectares (ou 23,55\% do território do município) de qualquer uso urbano, exceto o de baixíssima densidade para alta renda.
O efeito imediato dessa estratégia de controle do uso e ocupação do solo foi um excesso de oferta de terra para a indústria (em 1990, aproximadamente 40\% das glebas destinadas para o uso industrial estavam vazios), levando a uma escassez de terra urbana destinada para uso residencial e outros. Essa equação, num contexto de altos índices de crescimento demográfico $(20,42 \%$ por ano nos anos 60 e 11,23\% nos anos 70), provocou uma expansão periférica, ocupando áreas não urbanizadas e consumindo vorazmente toda a terra não destinada para usos industriais, inclusive as áreas de preservação ambiental. Sem outra alternativa, com uma oferta quase inexistente de zonas destinadas para os pequenos lotes residenciais de baixa renda, a expansão urbana foi, em sua maior parte, irregular, feita por mercados informais que não se adequavam a qualquer padrão de urbanização. ${ }^{8} \mathrm{O}$ resultado foi que no início dos anos 80 apenas $30 \%$ das ruas existentes eram pavimentadas, $50 \%$ dos domicílios estavam conectados à rede de água e a taxa de mortalidade infantil era de 83/1.000 (Prefeitura de Diadema, 1995b).

Esse padrão guarda algumas semelhanças com o caso de Guarujá, localizado na periferia de uma região de crescimento rápido - a Baixada Santista, onde instalaram-se indústrias (a maior parte em Cubatão) e equipamentos portuários (a maior parte em Santos). ${ }^{9}$ Trabalhadores que não tinham acesso a terra e habitação na área urbanizada de Santos assentaram-se na porção noroeste da ilha vizinha de Guarujá, formando o núcleo de Vicente de Carvalho, próximo ao canal que liga à ilha de Santos. Como Diadema, nos anos 60 e 70, o município de Guarujá atraiu como população permanente quase exclusivamente migrantes de baixa renda, pois funcionários mais qualificados das indústrias da Baixada residiam em Santos ou São Paulo.

Mas Guarujá combina a "cidade-dormitório" ao turismo, utilizando sua porção Sudeste como um balneário. A "Pérola do Atlântico". ${ }^{10}$ Neste caso, a estratégia do Plano Diretor de Guarujá (de autoria de Jaime Lerner, aprovado em 1978) e de sua legislação urbanística era preservar as áreas mais bem urbanizadas para o uso balneário e simplesmente "esquecer" os mercados residenciais de baixa renda, em um contexto de grande crescimento demográfico. ${ }^{11} \mathrm{~A}$ orla urbanizada - que sempre contou com rede de água e saneamento, pavimentação e iluminação e constantes investimentos em confortos urbanos - foi minuciosamente zoneada para os diferentes segmentos de mercado de veraneio, bloqueando seu acesso a mercados residenciais de baixa renda. Este objetivo foi atingido fixando-se padrões urbanísticos completamente estranhos às 
lógicas econômicas e espaciais dos assentamentos de baixa renda, ou seja, lotes de $500 \mathrm{~m}^{2}$ de área mínima, para residências unifamiliares, prédios de apartamentos com grandes recuos, etc.

Ao mesmo tempo, assentamentos populares para a população permanente expandiram-se em Vicente de Carvalho sobre mangues, e favelas formaram-se em morros voltados para o continente. Com esse padrão de urbanização, foi possível proteger investimentos nos balneários de fim de semana, afastando a "invasão", pelos pobres, de áreas ricas e urbanizadas.

O que acabamos de descrever, em ambos os casos, são mecanismos perversos que mantêm a pobreza longe das áreas mais bem urbanizadas, construindo uma muralha por meio de regulação urbanística e reservando as regiões mais qualificadas aos mercados formais - e abrindo continuamente fronteiras de expansão urbana para o informal. $\mathrm{O}$ mecanismo revela-se ainda mais perverso se levarmos em conta que a "fronteira" aberta pelos mercados informais não foi ocupada pelos mercados formais, devido às dificuldades para sua urbanização (altas declividades ou áreas inundáveis) ou a restrições ligadas à preservação ambiental (como áreas de mangue, matas, mananciais, etc.).

Os exemplos de Diadema e Guarujá, dois municípios com altos índices de exclusão territorial, demonstram o fracasso do planejamento e dos paradigmas da regulação urbanística que foram aplicados em cidades do Estado de São Paulo nos anos 70 e 80 .
O Gráfico 1 faz o cruzamento do ranking da regulação urbanística (da mais regulada à menos regulada $)^{12}$ com o ranking da exclusão territorial (da maior porcentagem de domicílios em situação adequada à menor), demonstrando que não há conexão entre a presença do planejamento urbano e o grau de exclusão territorial das cidades. Contrariamente ao conhecimento convencional de que o problema das cidades brasileiras é a "falta de planejamento", os resultados da pesquisa demonstram que o planejamento, como foi majoritariamente praticado até o final dos anos 80, tem um impacto muito pequeno no equilíbrio socioambiental das cidades. Em um contexto de alta pressão demográfica e competição pelo solo urbano, o planejamento - e, mais especificamente, o zoneamento foi largamente utilizado como um instrumento para assegurar segregação e demarcação de segmentos de mercado. Esta é uma das razões por que o planejamento urbano, suas estratégias e sua relação com a gestão urbana devem ser profundamente repensados, se quisermos que este incida sobre o urbanismo de risco. ${ }^{13}$

Até esse ponto, não comentamos o outro extremo do ranking - as cidades com a melhor performance no provimento de condições de vida adequadas para seus habitantes. Apesar de não haver cidade no Estado com 100\% de domicílios que disponham de condições urbanísticas adequadas, os menos precários localizam-se na porção noroeste do Estado. ${ }^{14}$ Nessa região, conhecida como a "Califórnia Paulista", floresceu a agroindústria, sobretu-

\section{GRÁFICO 1}

Distribuição da Regularidade Urbanística X Exclusão Territorial com Legislação Urbanística Aprovada até 1991

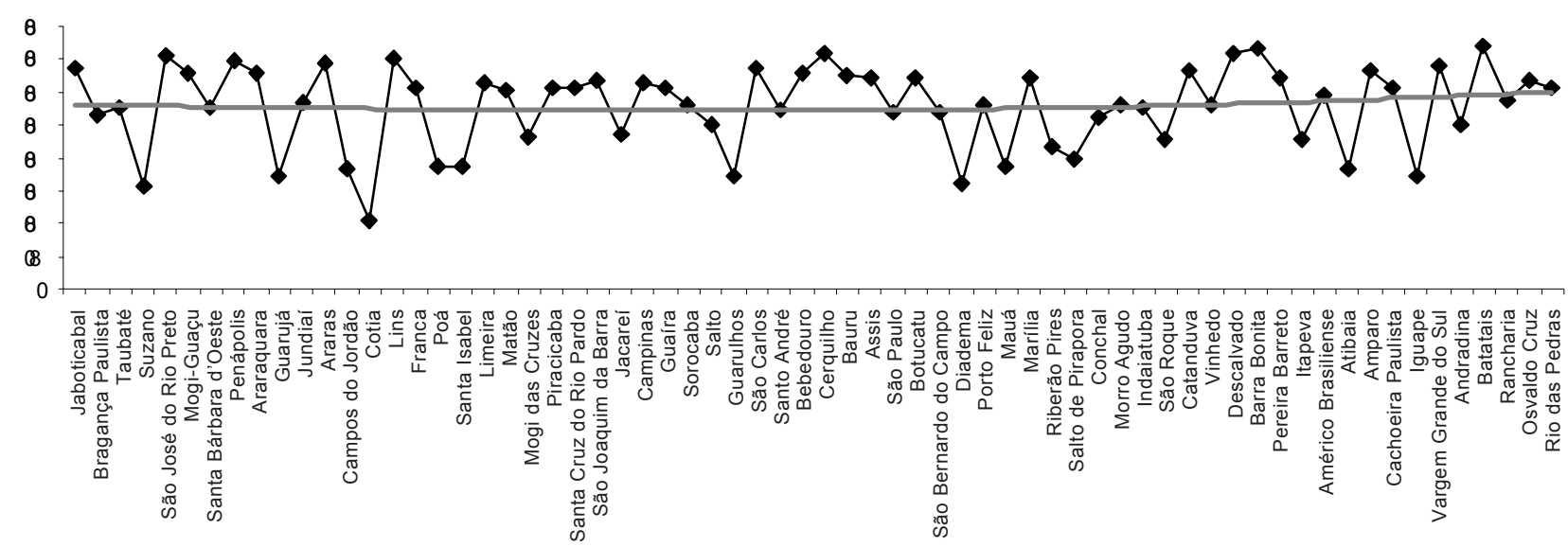

Fonte: Censo Demográfico IBGE 1991/Tabulação Especial Aurílio Caiado e Pesquisa Impacto da Aplicação de Novos Instrumentos Urbanísticos 1998. 
do ligada à cana-de-açúcar e à laranja. Tomando o exemplo da região de Ribeirão Preto, onde o complexo sucroalcooleiro estabeleceu-se nos anos 70, a maior parte das cidades possui altos índices de adequação e condições de vida, apesar de a concentração de renda ser semelhante à do Município de São Paulo, e os níveis salariais inferiores.

\section{AS CIDADES AGROINDUSTRIAIS "FECHADAS"}

Apesar de os anos 70 - quando o Proálcool foi lançado e consolidado - terem sido de expansão econômica, a taxa de crescimento populacional da região de Ribeirão Preto $(2,45 \%$ por ano) foi menor que da média do Estado para esse período (3,5\% anuais) (Fundação IBGE, 1971). Durante os anos 80, os efeitos da recessão foram muito mais agudos na Região Metropolitana de São Paulo e na Baixada Santista do que na região de Ribeirão Preto, que continuou a crescer, apresentando taxas de crescimento $(2,59 \%)$ ligeiramente mais altas do que a média do Estado $(2,02 \%)$ (Fundação IBGE, 1981). A região atrai migrantes nos anos 70 e 80 , mas nunca na mesma escala que os centros industriais e suas periferias.

A explicação dessa situação reside na relação entre atividade econômica e urbanização. O complexo sucroalcooleiro, como todos os setores agroindustriais, possui seu centro dinâmico fora das áreas urbanas. A lógica de instalação da agroindústria é baseada na proximidade de áreas de produção de produtos primários de forma mais acentuada do que nas economias de aglomeração. Assim, não há concentração em uma única cidade-pólo, mas um espraiamento em diferentes cidades onde se localizam as usinas. A terra para cultivo valoriza-se como resultado de desenvolvimento agroindustrial, criando uma barreira para a conversão em terra urbana, mesmo durante ciclos de expansão econômica e demográfica (Caiado, 1992).

O mercado de trabalho é majoritariamente sazonal - absorve mão-de-obra apenas durante as safras, pois a maior parte do cultivo foi mecanizado e a terra foi concentrada em grandes latifúndios. Em períodos de colheita, migrantes assentam-se em acampamentos dentro das usinas, ou em quartos alugados, principalmente nas cidades menores da região. Para impedir a instalação permanente desses trabalhadores sazonais, as cidades estabelecem postos de controle nas estradas, estações rodoviárias e ferroviárias e até bloqueios com "batidas" na entrada das cidades.

Com menor pressão sobre a terra urbana, e portanto preços muito baixos (comparando-se com Diadema ou Guarujá), e permanecendo parte da receita proveniente
TABELA 2

Preços Relativos de Terra

Estado de São Paulo - 1998

\begin{tabular}{lrrc}
\hline Indicadores & Diadema & Guarujá & Jaboticabal \\
\hline Preço Médio $(R \$)$ & 206,00 & 416,13 & 41,00 \\
Preço Mais Caro $(R \$)$ & 273,00 & 870,00 & 100,00 \\
Preço Mais Barato $(R \$)$ & 83,00 & 14,23 & 14,23 \\
Relação entre os Dois Extremos (\%) & 3,29 & 37,00 & 7,03
\end{tabular}

Fonte: Diadema - PMD - Banco de Dados sobre o valor do preço da terra, 1991/1998. Guarujá - PMG - Planta de Valores Genéricos 1998. Jaboticabal - pesquisa de preços feita com corretores.

da produção agroindustrial nas cidades, é possível o investimento mais generalizado em infra-estrutura, gerando disparidades menores nos preços relativos (Tabela 2).

Neste caso, a população de baixa renda - mesmo considerando os baixos salários e a alta concentração de renda - tem mais acesso à habitação adequada. Quando a oferta de terra urbanizada responde à demanda, não se cria o fenômeno da supervalorização da terra urbanizada; portanto, há menor exclusão territorial.

Entretanto, este modelo viabilizou-se apenas em uma escala regional, pois os pobres que não penetram nas cidades assentam-se em outras localidades, em condições precárias. Além disso, todo o sistema é dependente quase exclusivamente da produção de cana-de-açúcar - que não absorve mão-de-obra, além de ter devastado o meio ambiente e de ter sido altamente subsidiada ao longo da história.

\section{EXCLUSÃO TERRITORIAL E VIOLÊNCIA NO ESTADO DE SÃO PAULO}

O crime e a violência no Brasil transformaram-se no centro das atenções tanto dos formuladores das políticas quanto do público. Durante os anos 80 , as taxas de morte violenta ${ }^{15}$ subiram do quarto para o segundo lugar dentre as causas de morte no país. O Brasil, com uma taxa de homicídios de 23,35 por 100 mil habitantes em 1988, (Ministério da Saúde, 1980-1989) é o segundo país mais violento da América Latina, a região mais violenta do mundo, perdendo apenas para a Colômbia (89,5 homicídios por 100 mil habitantes) no final dos anos 80 (Ayres, 1998). Com uma taxa de homicídio de 28,79 por 100 mil em 1991, e 29,70 em 1994, o Estado de São Paulo está acima da média brasileira, e pode ser considerado o Estado mais violento do Brasil. ${ }^{16}$

Muito já se escreveu sobre criminalidade e violência e sobre sua relação com o uso ilegal e o tráfico de drogas. 
Mas é difícil generalizar-se a suposição de que as principais causas de crime e violência estariam no uso ou tráfico de drogas, pois estes são problemas que afetam cada cidade de forma específica. Mais provavelmente, tanto o aumento da violência quanto do tráfico são sintomas da mesma causa.

Explicações tradicionais relacionam violência e marginalização social à inabilidade de migrantes de origem rural de realizar a transição da tradição para a modernidade. No caso de São Paulo, o argumento não se aplica, pois a violência aumentou nos anos 80 , quando se verifica um forte declínio no êxodo rural, e o Estado - particularmente a Região Metropolitana de São Paulo - começava a passar por sua transição demográfica (declínio da taxa de crescimento da população, taxas de fertilidade e transformação dos padrões regionais de migração) (Berquó, 1992).

Os dados do Censo de 1991 mostram que a capital perdeu 900 mil habitantes nos anos 80 , e sua região metropolitana teve um fluxo positivo de migração de $450 \mathrm{mil}$, a maior parte migrantes vindo do município central para a periferia da mesma região (Ribeiro e Lago, 1995).

Um forte argumento na literatura recente liga a violência à pobreza. O nexo é sustentado por dados mostrando que aumentos de violência ocorreram em períodos nos quais houve também fortes aumentos da pobreza. A recessão dos anos 80 e os efeitos do ajuste estrutural sobre os pobres urbanos levaram a uma severa diminuição dos salários reais e das oportunidades de emprego a grandes segmentos da força de trabalho (Ayres, 1998). Apesar de essas afirmações serem verdadeiras no caso de São Paulo, a pobreza absoluta em si não pode explicar por que a Região Metropolitana de São Paulo é a mais violenta entre as metrópoles brasileiras. De fato, a proporção da população abaixo da linha de pobreza em São Paulo em 1989 $(20,90 \%)$ é uma das mais baixas entre todas a metrópoles brasileiras. Salvador, com $39,0 \%$ a população abaixo da linha de pobreza, é uma das menos violentas, com uma taxa de homicídios de 17,5 por 100 mil habitantes (Singer, 1997).

Certamente, a desigualdade (ou a pobreza relativa) deve ser levada em consideração para explicar-se altas taxas de criminalidade, como apontam alguns estudos em cidades norte-americanas (Freeman, 1996). Mas a pobreza, a desigualdade e até mesmo transformações no mercado de trabalho podem ser tratadas de formas diferentes por comunidades e indivíduos, dependendo de sua vulnerabilidade (Moser, 1996). De acordo com Moser, o conceito de vulnerabilidade, ou de insegurança do bem- estar de indivíduos, famílias ou comunidades diante de um ambiente em transformação capta não apenas a situação de indivíduos e grupos, mas também seus meios de resistência ou os recursos que podem mobilizar em face das turbulências.

Nossa hipótese é que a exclusão territorial torna indivíduos, famílias e comunidades particularmente vulneráveis, abrindo espaço para a violência e ao conflito. O nexo entre violência e exclusão territorial é muito claro quando cruzamos os dados de homicídios com os índices de exclusão territorial (expressos na porcentagem de domicílios em situação adequada) para os 118 municípios pesquisados (Tabela 3 ).

Entre os 28 municípios com pior situação de exclusão territorial (grupos 3 e 4 na Tabela 1), de Embu-Guaçu 1,30 dos domicílios em situação adequada - a Poá $39,52 \%-, 25$ possuem os piores indicadores. O oposto também é verdadeiro: entre os 21 municípios mais bem situados em termos de adequação, 14 são os menos violentos no Estado. Exceções neste caso são Ribeirão Preto e São José do Rio Preto, conhecidos centros em rotas de tráfico de drogas.

A exclusão territorial produz uma vida diária insegura e arriscada, bloqueia acesso a empregos, a oportunidades educacionais e culturais, que estão concentradas em enclaves pequenos e protegidos dentro das cidades. Ela nega a possibilidade de se utilizarem recursos como a casa própria para gerar renda e criar empregos, na medida em que a maior parte das casas é ilegal e o uso misto é geralmente proibido pelas normas de uso do solo municipal.

Os territórios excluídos constituíram-se à revelia da presença do Estado - ou de qualquer esfera pública - e, portanto, desenvolvem-se sem qualquer controle ou assistência. Serviços públicos, quando existentes, são mais precários do que em outras partes das cidades; trabalhar nessas áreas muitas vezes é visto pelos funcionários públicos como "castigo". Mais do que isso, viver permanentemente sob uma condição de privação de necessidades ambientais básicas faz os habitantes se sentirem como se suas vidas tivessem pouco valor.

Recentes estudos sobre violência demonstram que o homicídio é a principal causa de mortalidade entre os jovens do sexo masculino de 15 a 24 anos de idade (Cardia, 1998). ${ }^{17}$ Se verificarmos as tendências demográficas das cidades com as maiores taxas de violência, todas elas passaram, nos anos 70, por imenso crescimento populacional, que começou a declinar nos anos 80. Diadema, Embu, Francisco Morato, entre outros, repetem o mesmo 
TABELA 3

Cidades com os Maiores Índices de Exclusão Territorial e Taxa de Homicídios (1)

Estado de São Paulo - 1991-1994

\begin{tabular}{|c|c|c|c|c|c|}
\hline \multirow[b]{2}{*}{ Menos Adequados } & \multirow{2}{*}{$\begin{array}{c}\text { Adequação } \\
(\%)\end{array}$} & \multicolumn{2}{|c|}{1991} & \multicolumn{2}{|c|}{1994} \\
\hline & & $\begin{array}{c}\text { Taxa de } \\
\text { Homicídios (1) }\end{array}$ & $\begin{array}{l}\text { Ranking } \\
\text { Violência }\end{array}$ & $\begin{array}{c}\text { Taxa de } \\
\text { Homicídios (1) }\end{array}$ & $\begin{array}{l}\text { Ranking } \\
\text { Violência }\end{array}$ \\
\hline 1. Embu-Guaçu & 1,3 & 44,95 & 9 & 25,04 & 29 \\
\hline 2. Arujá & 6,26 & 18,85 & 36 & 33,49 & 19 \\
\hline 3. Juquitiba & 6,45 & 50,68 & 6 & 36,36 & 16 \\
\hline 4. Francisco Morato & 7,46 & 58,34 & 3 & 76,36 & 3 \\
\hline 5. Cubatão & 10,07 & 37,42 & 16 & 31,24 & 20 \\
\hline 6. Rio Grande da Serra & 16,94 & 30,33 & 19 & 49,35 & 7 \\
\hline 7. Praia Grande & 18,14 & 44,95 & 10 & 14,64 & 48 \\
\hline 8. Cotia & 20,64 & 36,89 & 17 & 20,79 & 34 \\
\hline 9. Embu & 23,06 & 78,84 & 2 & 76,43 & 2 \\
\hline 10. Santana de Parnaíba & 25,92 & 10,86 & 64 & 26,68 & 27 \\
\hline 11. São Vicente & 26 & 20,19 & 31 & 26,68 & 26 \\
\hline 12. Caraguatatuba & 26,88 & 45,61 & 8 & 25,65 & 28 \\
\hline 13. São Sebastião & 28,36 & 50,68 & 5 & 54,3 & 5 \\
\hline 14. Franco da Rocha & 28,89 & 25,91 & 24 & 60,28 & 4 \\
\hline 15. Cajamar & 30,12 & 44,78 & 12 & 29,87 & 25 \\
\hline 16. Mongaguá & 30,17 & 26,62 & 21 & 9,08 & 75 \\
\hline 17. Monte Mor & 31,14 & 15,82 & 44 & 40,8 & 10 \\
\hline 18. Suzano & 31,44 & 25,94 & 23 & 40,6 & 11 \\
\hline 19. Diadema & 31,8 & 85,58 & 1 & 76,89 & 1 \\
\hline 20. Várzea Paulista & 33,38 & 19,1 & 34 & 20,83 & 33 \\
\hline 21. Guarujá & 34,11 & 26,34 & 22 & 35,14 & 18 \\
\hline 22. Iguape & 34,34 & 14,38 & 49 & 11,33 & 58 \\
\hline 23. Guarulhos & 34,46 & 44,12 & 13 & 53,89 & 6 \\
\hline 24. Atibaia & 36,38 & 15,17 & 47 & 18,01 & 41 \\
\hline 25. Campos do Jordão & 36,65 & 21,69 & 29 & 22,42 & 30 \\
\hline 26. Mauá & 37,03 & 58 & 4 & 38,94 & 14 \\
\hline 27. Santa Isabel & 37,17 & 15,87 & 43 & 37,15 & 15 \\
\hline 28. Poá & 37,34 & 39,52 & 15 & 20,62 & 36 \\
\hline
\end{tabular}

Fonte: Fundação IBGE. Censo de 1991; Fundação Seade. Sistema de Informações sobre Mortalidade. (1) Por 100 mil habitantes.

padrão. Essas tendências podem ser interpretadas em termos generacionais: a violência cresce nos anos subseqüentes ao grande crescimento populacional. Jovens, nascidos nos anos 70, viveram todas as suas vidas em situação de exclusão territorial, e, portanto, sob condições de extrema vulnerabilidade. Por volta do final dos anos 80 , quando chega a hora de sua inclusão no mercado de trabalho e formação de famílias, não existem empregos nem meios disponíveis para enfrentar a situação. A violência então toma conta, com seu sentido ambíguo de desespero e heroísmo.

Os resultados da pesquisa que acabamos de expor trazem evidências da ligação entre exclusão territorial e violência, e de sua relação com modelos de desenvolvimento econômico e políticas de planejamento urbano. Uma questão final deve ainda ser colocada:

\section{COMO AS POLÍTICAS URBANAS PODEM ENFRENTAR A EXCLUSÃO TERRITORIAL?}

O approach tradicional do planejamento em relação aos assentamentos de baixa renda tem sido "esquecer" ou estigmatizar estes territórios (denominando-os "subnormais") e investir neles politicamente. Investir politicamente significa negociar, em geral usando votos como moeda de barganha, provendo investimento em infra-estrutura e serviços como "concessões" ou "favores" do prefeito ou vereador para as comunidades. Este mecanismo tem sido uma fonte muito importante de poder político na esfera local, na medida em que assentamentos irregulares ou ilegais não têm o mesmo direito à infra-estrutura e a serviços que a cidade legal. $\mathrm{O}$ estatuto ilegal de seu ambiente 
torna os habitantes de baixa renda ainda mais vulneráveis ao clientelismo.

O caso de Guarujá é muito representativo dessa estratégia política. Alguns assentamentos irregulares foram até mesmo promovidos por vereadores ou interlocutores do prefeito, que distribuíram documentos "frios" atribuindo direito à ocupação de terras não urbanizadas.

Mas o caso de Diadema demonstra que uma política urbana diferente pode levar a transformações substanciais em taxas de exclusão territorial.

Como vimos, tanto Diadema quanto Guarujá cresceram rapidamente durante mais de duas décadas e implementaram sistemas tradicionais de planejamento urbano nos anos 70. Entretanto, nos anos 80, as experiências começam a diferenciar-se: enquanto em Diadema implementaram-se políticas para superar a exclusão territorial, no Guarujá o poder público municipal mantém as práticas tradicionais de planejamento, exacerbando a exclusão.

Diadema investiu pesadamente em regularização fundiária, implantação massiva de infra-estrutura, urbanização de favelas e na transformação de sua estratégia de regulação urbanística, introduzindo em seu Plano Dire- tor instrumentos destinados a ampliar a oferta de terra urbanizada para mercados de baixa renda. ${ }^{18}$

A diferença entre as duas experiências - e seus resultados - é fundamentalmente política. Diadema, devido à sua posição no $\mathrm{ABC}$, havia experimentado a organização popular através de sindicatos no início dos anos 80. Iniciando com um fundo criado por famílias e amigos de trabalhadores em greve, uma rede de cooperativas de compras alimentares, associações de moradia e movimentos articularam-se, gerando uma importante fonte de capital social na cidade. Esses grupos organizados começaram a demandar do governo municipal a intervenção nas condições urbanas. Em 1982, um prefeito local foi eleito com a sustentação dessas redes e, a partir daquele momento, comunidades em Diadema transformaram-se em interlocutores permanentes das políticas públicas, participando nas negociações em torno de estratégias de regulação urbanística e decisões relacionadas ao investimento público. Em 1995, 121 favelas das 197 existentes tinham sido urbanizadas, a rede de água cobria 95\% dos domicílios e a rede de esgotos chegava a $60 \%$ deles, $96 \%$ das ruas eram pavimentadas e iluminadas e a taxa de mortalidade in-

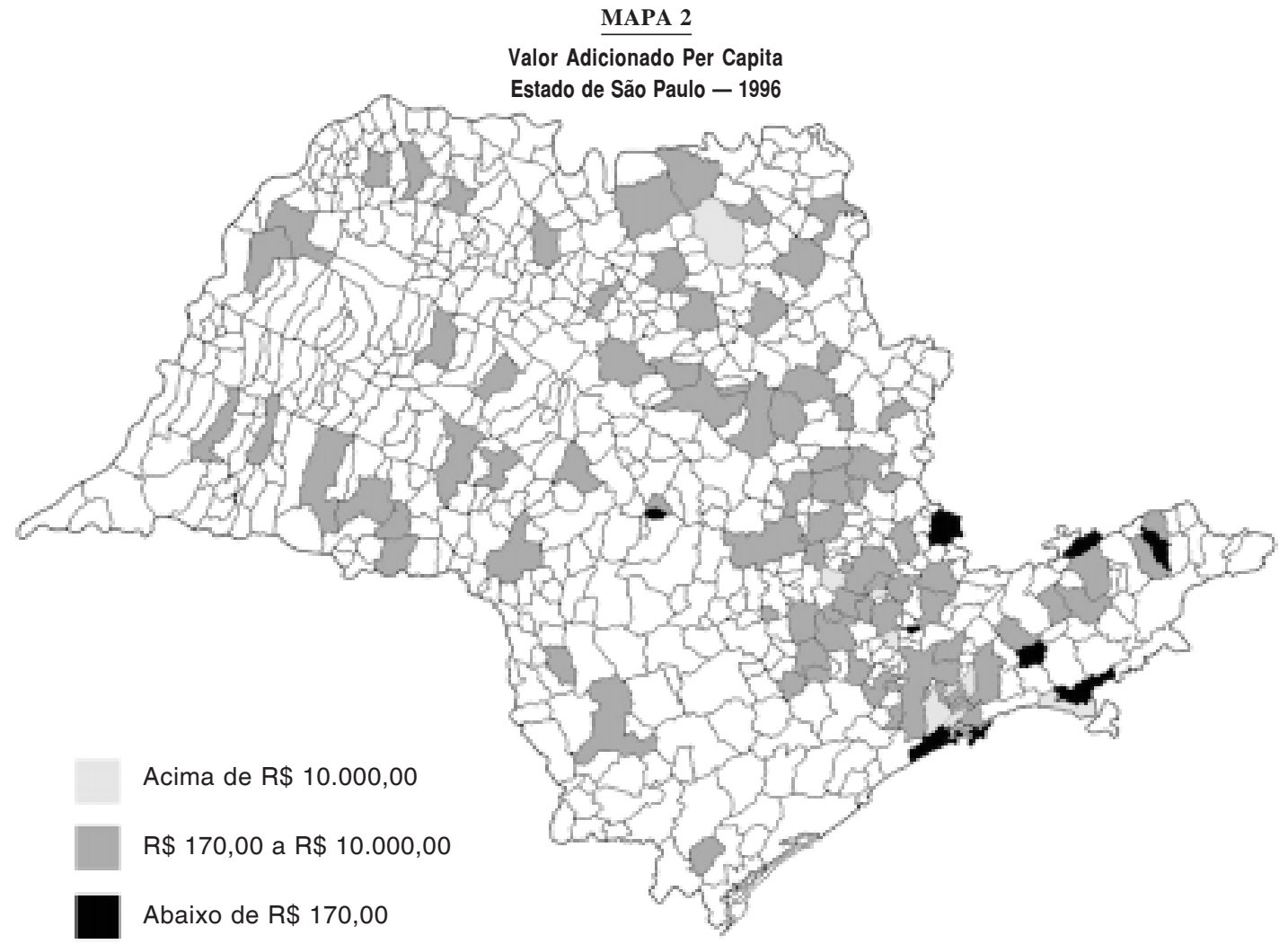

Fonte: Fundação Seade. Perfil Municipal.

Nota: Valores em Reais de dez./95 pelo IGP-DI da FGV. 
fantil caiu de 83/1.000 no início dos anos 80 para 21/1.000 em meados dos 90.

Mantendo suas políticas tradicionais, e diante de sua primeira crise como cidade balneária, os indicadores de Guarujá se deterioraram: das 17 favelas existentes em 1980 , passou-se atualmente a 57 , onde vivem $47 \%$ da população do município; apenas $43,09 \%$ da cidade está conectada à rede de água e $6,17 \%$ à rede de esgotos. ${ }^{19}$

A exclusão territorial, portanto, não é uma fatalidade ou um tema que deva ser tratado apenas em termos econômicos. O caso de Diadema, assim como outros exemplos de sucesso no Brasil, demonstra que a existência de capital social e a disposição do poder público em dividir poder com as comunidades de baixa renda são essenciais para transformar a urbanização de risco rumo a um modelo mais igualitário e sustentável, com menos perigo de gerar violência.

\section{NOTAS}

1. O relatório final da pesquisa encontra-se disponível sob a forma de CD-ROM. 2. Este número corresponde ao total de municípios com população acima de 20 mil habitantes no Estado de São Paulo. O recorte foi estabelecido com base em artigo constitucional de 1988, que determina que todos os municípios com mais de 20 mil habitantes são obrigados a implementar processos de planejamento e regulação urbanística em seu território. A mesma determinação já existia anteriormente, desde 1975, quando um decreto federal restringira o acesso dos municípios a créditos e empréstimos federais (inclusive à cooperação internacional) para expansão de infra-estrutura e serviços àqueles que apresentassem um plano diretor municipal justificando o projeto em questão.

3. Plano Diretor, Leis de Uso e Ocupação do Solo e outras normas que compõem estratégias de regulação urbanística foram consideradas.

4. A metodologia e o tratamento dos dados foram desenhados por Aurílio Caiado. Para avaliar infra-estrutura, foram levadas em consideração quatro variáveis: rede de água e esgotos, coleta de lixo e iluminação pública. Se o domicílio está conectado ao sistema de água encanada, é considerado adequado; todos os outros sistemas (poços, açudes, acessos públicos coletivos, etc.) são considerados inadequados. Para esgotos, sistemas públicos ou fossas sépticas são considerados adequados, enquanto todas as outras soluções (queimar os detritos, enterrálos, deixá-los em terrenos vazios, despejá-los nos rios, lagoas ou mar) são consideradas inadequadas. Para iluminação pública, considera-se adequado o sistema elétrico com relógios nos domicílios, e todas as outras soluções (sistema elétrico sem relógios, sistemas a óleo ou querosene são inadequadas).

Em relação às condições de habitação, foram consideradas adequadas habitações com paredes de alvenaria, madeira aparelhada ou taipa não revestida, com cobertura de laje de concreto, telha de barro, cimento amianto, zinco ou madeira aparelhada. Habitações feitas de palha ou materiais aproveitados foram consideradas inadequadas, assim como domicílios improvisados ou habitações coletivas (cortiços).

5. Trabalhamos principalmente com a taxa de homicídios per capita, porque este é o indicador mais confiável para medir a violência registrado por autoridades de saúde pública, que possuem um sistema muito consolidado de registro de mortes por causa no Estado de São Paulo.

6. Woodrow Wilson International Center for Scholars - Comparative Urban Studies Project on Urbanization, Population, Security, and the Environment. Grupo de estudos sobre população, ambiente, urbanização e segurança, Washington, 1998/99.

7. A região mais pobre do Estado é o Vale do Ribeira, a sudeste do Estado, que compreende 14 municípios e 226,413 habitantes, $45,17 \%$ deles considerados indigentes. As periferias da capital, ou 38 municípios, possuem 6 milhões de habitantes, $5 \%$ dos quais considerados indigentes.
8. Do total de 380 loteamentos registrados no município atualmente, 290 são irregulares - a maioria tendo sido aberta nos anos 70 (118). (Prefeitura de Diadema, 1995a).

9. Alguns terminais de containers privados, como os da Dow Chemical, Cargill e Cutrale, instalaram-se no Guarujá nos anos 70, definindo assim um retroporto. 10. A primeira ocupação da ilha ocorre quando a Companhia Balneária da Ilha de Santo Amaro estabelece um hotel, um cassino e 50 chalés para a elite paulistana na última década do século XIX.

11. O crescimento populacional de Guarujá nos anos 70 foi de $5,26 \%$ anuais.

12. Considerando a legislação aprovada até o final dos anos 80 , já que esta informação foi cruzada com os dados do Censo de 1991

13. A atuação do Fórum Nacional da Reforma Urbana foi importante nesse sentido. A partir de organizações populares, comunidades eclesiais de base e setores técnicos comprometidos com democratização do acesso à terra e infra-estrutura urbana, formou-se a partir da redemocratização uma rede de agentes cuja identidade era questionar os compromissos e efeitos da política urbana tradicionalmente praticada no país. A partir desse movimento - que culmina com a introdução de uma pauta popular e democrática no capítulo de política urbana da nova Constituição de 1988 -, pautas como a exclusão praticada pela própria legislação são incluídas na discussão sobre política urbana.

14. De acordo com a Tabela 1, os melhores indicadores correspondem aos municípios de Batatais (74\%); Cerquilho (71,61\%); Descalvado (71,58\%); e São José do Rio Preto $(70,72 \%)$.

15. Nas estatísticas de saúde pública, o grupo abrange todo os acidentes, incluindo de trânsito, suicídios, homicídios e outras causas violentas, segundo os códigos E800 a E999 do capítulo XVII do CID (Classificação Internacional de Doenças) (Souza, 1994)

16. Dados disponíveis do Estado de São Paulo no período 1991-94 (Fundação Seade), mas não são disponíveis para todos os estados. Entretanto, dados comparativos das regiões metropolitanas e suas capitais confirmam a posição de São Paulo. Mesmo tendo havido um aumento das taxas em todas as regiões metropolitanas, a taxa de homicídios de São Paulo foi de 38,9, a maior, seguida por Recife $(37,8)$. Souza (1994) aponta uma distorção nos números do Rio de Janeiro: se levarmos em conta o número de homicídios mais as mortes causadas por armas de fogo, cuja intencionalidade ou acidentalidade era ignorada, a taxa de homicídios no Rio de Janeiro em 1988 sobe a 50,3

17. O número crescente de homicídios entre jovens do sexo masculino é uma tendência internacional. Nos Estados Unidos, em 1987, no auge da epidemia de consumo de crack, 4.223 jovens homens entre 15 e 24 anos de idade foram assassinados. No mesmo ano, apenas no Estado de São Paulo, 3.171 homens jovens foram mortos (Cardia, 1998).

18. Entre os instrumentos utilizados em Diadema, foram criadas as Zonas de Especial Interesse Social (Zeis), em terrenos anteriormente destinados a usos industriais, tendo sido feitos créditos para que cooperativas de moradia pudessem comprar as terras e construir suas casas.

19. Dados da Prefeitura do Município do Guarujá, 1998.

\section{REFERÊNCIAS BIBLIOGRÁFICAS}

ADORNO, S. "La criminalidad violenta urbana en Brasil: tendencias y caracteristicas". Reunion sobre el desafio de la violencia criminal urbana. Rio de Janeiro, Interamerican Development Bank, 1997.

AYRES, R.L. "Crime and violence as development issues in Latin America and the Caribbean". Viewpoints. Washington, DC, The World Bank. Latin American and Caribbean Studies, 1998.

AKERMAN, M. et alii. Mapa de risco da violência na cidade de São Paulo. São Paulo, Cedec, 1996.

BAECHLER, G. "Why environmental transformation causes violence: a synthesis". The environmental change and security project report. Washington, Woodrow Wilson Center, 1998.

BERQUÓ, E. “1991: um Censo problemático”. Novos Estudos Cebrap. São Paulo, Cebrap, n.3, mar. 1992.

BIDERMAN, C. e LEME, M.C. "O mapa das desigualdades no Estado de São Paulo". Novos Estudos Cebrap. São Paulo, n.49, nov. 1997.

CAIADO, A. "A aglomeração urbana de Ribeirão Preto". Relatório de pesquisa do projeto Urbanização e metropolização no Estado de São Paulo. Campinas, Nesur/IE/Unicamp, Fundação Seade, Fecamp, 1992. 
"Dinâmica espacial e rede urbana paulista". São Paulo em Perspectiva. São Paulo, Fundação Seade, v.9, n.3, 1996.

CALDEIRA, T.P.R. City of walls: crimes, segregation and citizenship in São Paulo. PhD Dissertation on anthropology. Berkeley, Graduate division of the University of California, 1992.

CARDIA, N. “A violência urbana e os jovens". In: PINHEIRO, P.S. et alii. São Paulo sem medo. Um diagnóstico da violência urbana. Rio de Janeiro, Garamond, 1998.

. "A paz na contramão da história". Ser médico. São Paulo, Conselho Regional de Medicina do Estado de São Paulo, 1998.

CASTEL, R. "La piege de la exclusion in lien social et politiques". Revue internacionale d'action communautaire n.34. Paris, 1995.

FARIA, V. "Social exclusion and Latin American analysis of poverty and deprivation". In: RODGERS, G. et alii (ed.). Social exclusion: rhetoric, reality, responses. Geneve, International Institute for Labour Studies/United Nations Development Programme, 1995.

FEIGUIN, D. e LIMA, R.S. Tempo de violência: medo e insegurança em São Paulo. São Paulo em Perspectiva. São Paulo, Fundação Seade, v.9, n.2, 1995.

FREEMAN, R. "Why do so many young American men commit crimes and what might we do about it?". Journal of Economic Perspectives, 10:1(winter), 1996.

FUNDAÇÃo SEADE. Anuário Estatístico do Estado de São Paulo. São Paulo, Fundação Seade, vários anos.

FUNDAÇÃO IBGE. Pesquisa Nacional por Amostra de Domicílios (PNAD). Brasília, IBGE, 1971, 1981, 1989.

GUNN, P. "Uma geografia da violência na Região Metropolitana de São Paulo nos anos 80". In: PINHEIRO, P.S. et alii. São Paulo sem medo. Um diagnóstico da violência urbana. Rio de Janeiro, Garamond, 1998.

HOMER-DIXON, T. F. "Environmental scarcities and violent conflict. Evidence from cases". International Security, 19:1, 1994

KAYANO, J. Evolução comparada da qualidade de vida nos municípios brasileiros 1983-1992-Diadema. São Paulo, Instituto Pólis, 1992.

LASHER, C. "U.S. population policy since Cairo conference". Environmental change and security project. Washington, The Woodrow Wilson Center, 1998.

MATTOS, F.A. "Estrutura ocupacional e distribuição de renda: regiões metropolitanas de São Paulo e Rio de Janeiro". São Paulo em Perspectiva. São Paulo, Fundação Seade, v.9, n.2, 1995.

MATHEWS, J.T. "Redefining security". Foreign affairs 68, 1989.

MINAYO, M.C. e SOUZA, E.R. "Violência para todos". Cadernos de Saúde Pública 9. Rio de Janeiro, Fundação Oswaldo Cruz, 1993.
MINISTÉRIO DA SAÚDE e CENEPI - Centro Nacional de Epidemiologia. Subsistema de informação sobre mortalidade. Brasília, Ministério da Saúde, 1980-1989.

MOSER, C. "Confronting crisis. A comparative study of household responses to poverty and vulnerability in four poor urban communities". Environmentally sustainable development studies and monographs series 8 . Washington, The World Bank, 1996.

NELSON, J. "Poverty, inequality and conflict in developing countries". Project on world security. New York, Rockfeller Brothers Fund, 1997.

PAUGAM, S. (ed.). L'exclusion: l'etat des savoirs. Paris, Editions La Decouverte, 1996.

PREFEITURA MUNICIPAL DE DIADEMA. Cadastro e banco de dados. Diadema, Secretaria de Habitação e Desenvolvimento Urbano, 1995a.

Sumário de dados sócio-econômicos. Diadema, Secretaria de Habitação e Desenvolvimento Urbano, 1995b.

PUTNAM, R. Making democracy work-civic traditions in modern Italy. Princeton, University Press, 1993.

RIBEIRO, L.C.Q. e LAGO, L.C. "Dinâmica metropolitana e novos padrões de desigualdade social”. São Paulo em Perspectiva. São Paulo, Fundação Seade, v.9, n.2, 1995.

RODGERS, G. "What is special about a 'social exclusion' approach?" In: RODGERS,G. et alii (ed.). Social exclusion: rhetoric, reality, responses. Geneve, International Institute for Labour Studies/United Nations Development Programme, 1995.

ROLNIK, R. A cidade e a lei. Legislação, política urbana e territórios na cidade de São Paulo. Studio Nobel/Fapesp, 1997.

ROLNIK, R. e CYMBALISTA, R. (eds.). Instrumentos urbanísticos contra a exclusão social. São Paulo, Instituto Pólis, 1997.

ROLNIK, R. et alii. Impacto da aplicação de novos instrumentos urbanísticos em cidades do Estado de São Paulo. Campinas, Pontifícia Universidade Católica de Campinas/Lincoln Institute of Land Policy (mimeo e CD-ROM), 1998.

SINGER, P. Social exclusion in Brazil. Geneve, International Institute for Labor Studies/Labor Institutions and Development Programme, 1997.

SOUZA, E.R. "Homicídios no Brasil: o grande vilão da saúde pública na década de 80". Cadernos de Saúde Pública 10. Rio de Janeiro, Fundação Oswaldo Cruz, 1994.

SPOSATI, A. et alii. Mapa da exclusão social da cidade de São Paulo. São Paulo, Educ, 1996.

THE UNITED NATIONS CENTRE FOR HUMAN SETTLEMENTS. Towards safer cities, Habitat debate. Special issue, march 1998, v.4, n.1. 